\title{
1. Approaching the knowledge society
}

The sociology of knowledge has a history as long as it is hidden. As far as we can presently understand, the first signs of a sociological approach to the multifaceted value of knowledge date back to the very beginnings of human history, and it was taken in order to tackle the coexistence of people from different cultures and knowledge bases. At points in human history during which such a task has become urgent, a pressing demand has been raised and a deep inquiry launched.

Since knowledge's emergence as the subject of debate among scholars, it has been a central philosophical topic - giving rise to the autonomous discipline of epistemology, which has been decisive in developing the path of the entire history of philosophy (as was masterfully pointed out by Ernst Cassirer, one of the twentieth-century philosophers who came closest to the sociology of knowledge). All of sociology's founding fathers, from Montesquieu to Karl Marx, from Georg Simmel to Max Weber and Émile Durkheim, also dealt with knowledge. More general attention has grown from the Second World War onwards. However, as numerous as references to knowledge are in classic thought, and despite the fact that deep insights have been uncovered in the social sciences, we have to recognize the sad fact that the sociology of knowledge is not yet organized as a discipline (Fagerberg et al. 2012). How has such a strange situation been possible?

To answer this question, which is indeed a sizeable mystery within the history of thought, we will provide a glimpse into the main contributions made by the study of knowledge, in terms of its origins, functioning and effects, that are relevant to social life. Our aim here is to create a point from which to start filling the gap between the growing attention widely devoted to knowledge and an emphasis on the knowledge society, on the one hand, and the scant consideration given to it by contemporary sociology and the resulting lack of a comprehensive theory, on the other. 


\section{THE SOCIOLOGY OF KNOWLEDGE: A LONG START}

Within the long path of sociology of knowledge we can distinguish four phases, in part chronologically subsequent to one another and in part logically different.

A prehistory of very long incubation, which is often behind the cultural tradition of historicism, deals with relativism in moral issues. As far as we can see (at least in the West), this phase dates back to the Homeric poems and ancient Greek historians, when the central question was raised regarding the relationship between knowledge, on the one hand, and the community within which it dwells, on the other. We will also consider ancient myths; however, for the moment we can limit ourselves to Homer's Odysseus: 'many cities of men he saw and learnt their minds'. It goes without saying that, as soon as people from a certain population meet people from a different population for the first time, the uncertainty of the practical confrontation raises the theoretical question of how it is possible to have ways of thinking as strongly rooted as they are apparently incompatible. Such is the case for Herodotus when, in dealing with the long enduring war between the Greeks and the Persians, he must confront the funerary cannibalism of the Indian Callatiae tribe with Greek traditions. He usefully recalls Pindar and his clause about the rational rule of morality: 'custom is lord of all'. While relativism is, then, strongly attacked by the most relevant philosophers of the ancient world - that is, Plato and Aristotle - modern scholars will repeatedly return to it. It has been a key problem across all of modernity; indeed, it has become one of its distinctive marks. It is also a major issue for our current global societies, as can easily be seen worldwide today. Dealing with knowledge, both as content and as a thought process, we are undoubtedly confronted with a strong thema (Holton 1973) which has still not been solved, either in theory or in practice.

More generally, and notwithstanding the growing attention that has been devoted to knowledge throughout the centuries and outside of the reign of philosophy proper, particularly since the origins of European humanism (see for example Roger Bacon, Dante Alighieri, Francesco Petrarca), humans realized very late that they were already living within a society full of knowledge. In other words, the 'table where angels' bread is eaten' (Dante Alighieri, Convivio) had been set well before public awareness arose of increased production of a resource that would 
change the anthropic lifeworld. Indeed, we still have deep misunderstandings of this subject today.

In approaching the modern scientific revolution, the thema became an obsession for physicists: during and after the Middle Ages, a profound change was observed in the relativity of measurements and laws of movement, due to differences in the position and velocity of the observer's system of reference, up until Galileo and Newton (see for example Clagett 1959). As we know, however, a very general solution in physics only came with Albert Einstein at the beginning of the twentieth century.

Furthermore, Michel de Montaigne dealt with relativity/relativism in a different context following the European discovery of very different civilizations in the New World, when he wrote, for example (1580-95, p.359): 'there is nothing barbarous and savage in this nation, by anything that I can gather, excepting, that everyone gives the title of barbarism to everything that is not in use in his own country.'

Francis Bacon raised the question of the autonomy of episteme from fallacious idòla, either from personal or societal sources. Galileo Galilei battled strongly, in the face of great personal peril, against the use of common sense to advance scientific knowledge (think of the confrontation between geocentrism, which was then taken for granted due to immediate, sensorial data, and the more abstract and predictive heliocentrism). Montesquieu deeply criticizes knowledge taken for granted within the Western way of life and civilization (think of his masterpiece, Lettres Persanes). The seventeenth century, then, saw the birth of a new and very peculiar public sphere, the first secular and supranational scientific community, which went over and beyond any fighting nation, culture and religion: knowledge was seen as having the power to liberate everybody (cf. Syfret 1948). The Enlightenment raised the relevance of knowledge for human development, both as the 'light' of intellectual reason and simultaneously as an engine to advance practical civilization and a problematic move away from the state of nature.

However, the young Marx, while studying Hegel's Philosophy of Right, gives a decisive nudge to sociology of knowledge through two different and connected contributions. First, ideas do not come one by one to the minds of people, but in the form of a totality of conceptions (as, indeed, had already been taught by Hegel). Second (and this is quite original), there was an intimate nexus between the totality of conception diffused in Germany (German ideology) and the actual Prussian State. Marx was then driven to formulate a general, complex, albeit strong nexus between economic life and the production of knowledge within 
a specific society, for which ideology was the given name. In brief, abstraction is always determined: as long as it unreflectively reproduces reality, pretending to be the absolute, the single and perfect representation of reality, it is and actually remains only an illegitimate, speculative hypostasis, abstractly empty and merely a reflection of a contingent, historical datum. In other words, the concrete is mistaken for the abstract, just as the abstract is mistaken for the concrete (double exchange) (cf. della Volpe 1950). This is nothing but a mere ideology with the ability to cover the concrete interest of maintaining the status quo: from this starts the double necessity of a reversal in both philosophy and politics. A truly scientific inquiry is still available through a historical-materialistic view of history, society and human beings themselves.

A deterministic causality can be too simplistically read behind historical materialism, as was undoubtedly the case for a long time. All in all, the Marxian contribution to the sociology of knowledge is a philosophically deep insight, well rooted in the Aristotelian and anti-Platonic tradition. Indeed, we had to wait until Max Weber (1904/05) for a contribution of equal relevance. In order to avoid any determinism while dealing with the nexus between knowledge and society, he argues for elective affinities between capitalistic values (the famous list of precepts specifically introduced by Benjamin Franklin, a sort of prototype if not a 'living Idealtypus' of a capitalist) and the Protestant work ethic (in a variant of Calvinism, much less precisely defined indeed).

Thorstein Veblen (1906), evoking the Humean concept of habit to solve the same conundrum, argues that one's habit of thought is imposed upon by the scheme of life running through the community in which $\mathrm{s} / \mathrm{he}$ is living, extending his analysis to the very particular case of a scientist. Veblen was also able to establish links (not causal, of course) between habit and scheme, both on a very long-term scale across human history and within a certain division of social labour.

Durkheim, for his part, coins the term collective representations to refer to pieces of knowledge interwoven with the social order, forming the manner in which society thinks of the world and of itself. However, if such deep concepts as time, space, cause, force, power, and so on, and the intellectual life built upon them, are but the product of the creative power of that super-individual reality which is society, there is a fundamental feedback (Durkheim 1912). As the power of society goes far beyond that of any individual, intellectual life is not only a precondition of individuals' sociality, but also reacts to the elements of society of which it is a product, triggering a coevolutionary process between knowl- 
edge and society. This circularity is an interesting way of avoiding any determinism, and will hereafter be of great interest when modelling the knowledge society. Moreover, Durkheim adds that, as society is a part of natural reality, the production of knowledge is a natural process and not a subjective one: there is therefore no room for relativism within a sociology of knowledge thought of as a science as worthy as the natural sciences. His concept of science can be rendered by Bunge (1993, p.217): 'Durkheim held that all logical ideas, in particular that of class inclusion, have a social (in particular religious) origin, but he did not claim that they have a social (in particular religious) content.'

In so doing, Durkheim (1912) should have anticipated the division between the context of discovery (an origin that is socially determined in some manner, without further specification) and the context of justification (content connected to the domain or Reason and/or facts, in some unspecified way) made by Hans Reichenbach (1938) within the philosophical movement named logical empiricism. Unfortunately, this demarcation between discovery and justification is untenable if we accept the social construction of both discoveries and justifications made by postpositivistic social scientists. Each sociocognitive process starts and ends within the historical context of cultural resources and the social organization of work.

Moreover, during the first decades of the previous century, attention to relativity/relativism spread within the social sciences as never before. While anthropologists such as Lucien Lévy-Bruhl (1922) argued for the relativization of mentality across different societies, Ernst Cassirer (1923/29) and José Ortega y Gasset (1923) spoke about the location and perspective of knowledge, wondering if the recent Einsteinian theory of relativity could be a philosophically dense solution to the problem within physics (Cassirer 1920; Ortega y Gasset 1921). Indeed, the perspective from which subjects of a mass society observe, know and take decisions becomes no more negligible. The 'problem of our time', in the opinion of Ortega y Gasset (1923), was to go beyond the rationalistic bifurcation of thought and life that took place with Socrates, bringing the former back within the remit of the latter. Therefore, any relativism dissolved within the aurora of a renovated 'historical reason' which closely resembled Marxian historical materialism, but without the economism and with a hint of existentialism.

However, Max Scheler was more considered as a sociologist of knowledge (1926). He openly (re)charged the opinion that relativism was an idea of self-rebuttal and self-dissolution, as had already been claimed 
since the time of Plato, and argued for an absolute order of the values and knowledge behind relativism, while recognizing that, time after time, a variety of real factors simply shed light onto particular aspects of reality.

\section{THE FOUNDATION OF A DISCIPLINE}

In the crescendo of work undertaken during the first decades of the last century, the most highly esteemed book by Karl Mannheim (1929/36) opened the sociology of knowledge to maturity. As has been widely acknowledged, Mannheim set out the first theory worthy of such a name in this field, starting precisely from the same problem of relativism/ relativity. Indeed, he noted that the observer and interpreter of reality lives and militates in a certain, socially defined position, such as an economic class or a specific generation, status or professional group, and so on. S/he never acts and thinks in the abstract. As a matter of fact, $\mathrm{s} /$ he is never alone while thinking; rather, $\mathrm{s} / \mathrm{he}$ is either together with certain people or against certain others, within groups that share the same position within a historically determined social field. Moreover, if each observation, interpretation and public claim is relative to this location, it is never one single idea with which we are confronted. Rather, we find Weltanschauungen, constellations, styles and organically integrated systems of thought and mentalities within which collective experiences are crystallized within our own minds. Some individuals obscure their own position within the actual social reality and, consciously or not, work to conserve it (total ideologies), while others see within it only what they wish to deny, to the neglect of everything else (utopias).

We can agree with Mannheim's important observation that relativism itself is a historical product of modern social (vertical) mobility, and one of its major distinctive features. Thus said, as soon as a common denominator is found in claims from different positions and each partiality is neutralized, it becomes possible to discover a social equation between social conditions and knowledge claims. As a consequence, a universal relationism can be formulated in such a way that, if the social condition (a particular position or general contingency) changes, knowledge also changes. It is worth noting that this is neither an (absolute) relativism, nor a (restated) absolutism: on the contrary, in our opinion, it is useful for a research programme to be pursued by the sociology of knowledge, and we will try to develop some steps forward on this pathway. 
Mannheim continued that intellectuals, or the free intelligentsia, as they are mostly detached from the social conflict for resources, should benefit from gaining a consciousness of reality starting from a dispassionate reconstruction of connections between claims and socially situated actors, and thus contributing to a general emancipation of societal conditionings. In other words, relationism, while postponing the certainty of truth, was seen as a brick from which social reality is constructed and a starting point for political engagement in social change.

This is exactly where Mannheim's contribution stopped, and he was also judged as being uncertain on this point by the most attentive of scholars. Werner Stark, one of them, still maintains that 'Social developments do not determine the content of scientific developments, simply because they do not determine natural facts' (Stark 1958, p.171). Moreover, Stark defended the idea of absolute reality, admitting it was possibly attained from different perspectives, rather similarly to Scheler. Mannheim, too, was firmly anchored to a positivistic approach to scientific knowledge which he believed to be an exception to existentially determined thought, that is, in the political, human and social sciences, as well as in daily life (Mannheim 1928 in Mannheim 1964). Anyway, the nexus between thought and social life appears to Mannheim so intimate that the sociology of knowledge has to deal with their reciprocal action as well as their appearing with just two planes, only phenomenologically distinguishable. In this way, the sciences (and sociology is no exception) are the continuation of the ancient fight for the dominion of the general interpretation of the being. While the latter also makes an appeal to the self-limiting caution of the sociology of knowledge due to its intrinsic reflexivity, the former will be useful in what follows to open up knowledge in all of its forms as a third dimension of human life, beyond individual and social life.

Just before passing to a new phase in the sociology of knowledge, let us mention that, in these same years, Antonio Gramsci (1929-35) was carrying out work on ideology and hegemony and, more generally, on the role of culture in both history and politics. In particular, reworking an idea by Sorel, he defined the conjunction of material forces and ideology as the historical bloc. The former are to be intended as the content (base, structure), and the latter as the corresponding form (superstructure) if it is historically organic, that is, sociologically necessary to the structure, and not just arbitrary, that is, only psychologically wanted. The distinction between sociologically necessary and psychologically wanted is a close reminder of the different objects dealt with, respectively, by Mannheim's 
total and partial ideology. Moreover, if a person acquires consciousness of his own social position and tasks within the superstructure, then there has to be a vital nexus of necessity between structure and superstructure, something like what exists between the skeleton and skin of an animal. As a general result, history-politics is constructed by nation-people together with intellectuals. The latter should be thought of as, it should be said, people who are professionally devoted to working on superstructure and its nexus with structure.

This is a quite interesting point on the nexus between knowledge (in terms of content and reflexivity) and politics (in view of a governance within the knowledge-society). However, we have to stop here for the moment, in order to account for a new phase in the several decades following these contributions, which is relevant to both the historical reconstruction and the theoretical foundations of the sociology of knowledge. 